\title{
The Dynamics Model and Dynamic Characteristics Analysis of Face Gear Transmission System Involving Tooth Flank's Temperature
}

\author{
${ }^{1}$ Laiu Di, ${ }^{1}$ Zhao Lei, ${ }^{1,2}$ Yu Guangbin, ${ }^{1}$ Qu Zhiguang, and ${ }^{1,2}$ Zhao Xingfu \\ ${ }^{1}$ School of Mechanical and Power Engineering, Harbin University of Science and \\ Technology, Harbin, Heilongjiang 150080, China \\ ${ }^{2}$ Harbin Institute of Technology, Harbin, Heilongjiang 150001, China
}

\begin{abstract}
Based on the lumped parameter theory and the gear transmission system's engagement theory, a nonlinear dynamics model of the face gear transmission system is established, which includes time-varying mesh stiffness, comprehensive transmission error, mesh damping and tooth flash temperature;To solve and analyze the model,it can be found that the tooth flank's maximum instantaneous temperature will be changed significantly when the face gear system is into engagement and out of engagement,and the tooth flank's relative velocity direction will change near the high and middle range of the tooth. With the change of the gear parameters, the temperature also changes. It will provide a theoretical basis for the study of the tooth surface gluing problem, gears meshing thermal stress and other issues.
\end{abstract}

Keywords: Face gear;tooth flank's temperatue; dynamic characteristics; modeling

\section{Introduction}

Face gear transmission is a form of gear transmission, which has the better advantages such as the higher operating speed,the smaller transmission error, the larger transmission power and the lower noise, it has been the main transmission type which is the shaft transfer rotary movement. It has been widely used in mechanical systems. Due to the result from the high speed and high load, the tooth flank's gluing problem has become one of the main reasons which cause face gear transmission failure.Many scholars have studied the gear flank's temperature problem. G. Deng [1] analyzed the initial temperature of the gear, and established of the empirical formula; Taburdagita [2] established a finite element model which study the change of temperature caused by friction; Vaishya [3-4] studied the friction of the gear system, and established a gear system dynamics model which accounted friction. In order to study the reason which causes the impact of the gear system, Walha [5-6] established a nonlinear dynamical model of the two-stage spur gear system.Based on Block theory and Hertz theory, the nonlinear dynamics model including the toothbacklash, time-varying mesh stiffness and error for the non-orthogonal face gear transmission system is established. Besides, the numerical calculation and analysis of the tooth maximum instantaneous temperature have important significance for the study of solving the gear's gluing problem.

\section{Tooth flank's Temperature of Face Gear Transmission}

For surface temperature, the heat was too late to radiate to the surrounding,so that For surface temperature, the heat was too late to the surrounding radiation, all calories transformed into tooth surface temperature.Base on the Block theory, the formula of tooth surface flash temperature $\Delta \lambda$ is obtained. 
(1)

$$
\Delta \lambda=\frac{u f_{\lambda} F v_{i}}{\left(\sqrt{g_{1} \rho_{1} c_{1} v_{1}}+\sqrt{g_{2} \rho_{2} c_{2} v_{2}}\right) \sqrt{B}}
$$

Where, $f_{i}$ is coefficient of the temperature rise, and $f_{i}=1.18 ; v_{i}(i=1,2)$ is tangential velocity $(\mathrm{m} / \mathrm{s}) ; r_{i}(i=1,2)$ is density $\left(\mathrm{kg} / \mathrm{m}^{3}\right) ; g_{i}(i=1,2)$ is thermal conductivity $\left(J / m g \llbracket s \square g\left[{ }^{\circ} C\right) ; c_{i}(i=1,2)\right.$ is the specific heat capacity; $B$ is the halfwidth of the cotact strip $(m) ; u$ is the coefficient of friction.Compositing all of the factors such as viscosity of oil film, the tooth surface relative speed, load size, and roughness of tooth surface, the formula is obtained.

$$
u=0.013\left(\frac{\sigma_{H} R_{a}}{\eta_{m} v_{12}}\right)^{0.25}
$$

Where, $\sigma_{H}$ is the tooth surface contact stress $(M P a) ; R_{a}$ is roughness $(u m) ; \eta_{m}$ is the Lubricants' dynamic viscosity which is in the body temperature ( $m \square \operatorname{Pa} g \llbracket S$ ); $v_{12}$ is the sum of the tangential velocity $(\mathrm{m} / \mathrm{s})$. The tangential velocity $v_{i}(i=1,2)$ is time-varying parameters, $r_{1}, r_{2}$ are the vector,so $\frac{d r_{1}}{d t}, \frac{d r_{2}}{d t}$ are the relative moving speed of the contact point.The sliding coefficients of gear system are:

$$
\begin{aligned}
& \text { 童 } h_{1}=\frac{d r_{1}-d r_{2}}{d r_{1}}=\frac{v_{12}}{d r_{1} / d t} \\
& \frac{1}{d r_{2}} h_{2}=\frac{d r_{2}-d r_{1}}{d r_{2} / d t}=\frac{v_{12}}{d}
\end{aligned}
$$

$$
s=\frac{n q}{v_{12} p}
$$

(4)

Where $q=\left(\omega_{1} \times r_{1}\right) \times \omega_{12}-\omega_{1} \times v_{12}, p=n \times \omega_{12}-\Delta n \times v_{12} \omega_{i}(i=1,2)$ is the angular velocity of the main driven wheel; $n$ is the normal vector.Then the tooth surface relative velocity $v_{i}(i=1,2)$ can be deduced.

$$
\begin{aligned}
& \frac{1}{v_{1}}=s v_{12} \\
& \frac{1}{1} v_{2}=(1+s) v_{12}
\end{aligned}
$$

The half-width of the cotact strip $B$ is time-varying parameters. Based on the Hertz theory, if the face gear system is in the case of high speed and high load, tooth surface will be in the normal load $F(\mathrm{~N} / \mathrm{m})$, the track of the point of transmission contact is a ellipse,the long axis is $a$, the short axis is $b$, and the half-width of the $\operatorname{cotact} \operatorname{strip} B$ is the long axis of the ellipse. 


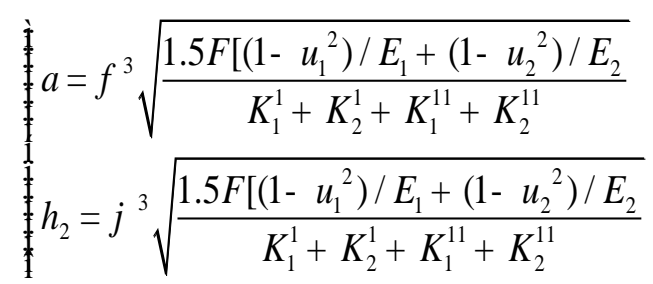

(6)

Where, $f, j$ is the elliptic integral function; ${ }^{u_{i}}(i=1,2)$ is poisson ratio of the gear $E_{i}(i=1,2)$ is modulus of elasticity; $K_{i}^{j}(i=1,2 ; j=1,11)$ is the curvature of the face gear tooth surface.

$$
t(r)=\frac{\sqrt{\left(K_{1}^{1}-K_{1}^{11}\right)^{2}+2\left(K_{1}^{1}-K_{1}^{11}\right)}}{\left(K_{2}^{1}-K_{2}^{11}\right) \cos 2 w+\left(K_{2}^{1}-K_{2}^{11}\right)^{2}}
$$

Bring into formula(6), $B$ can be obtained.

\section{Tooth Profile Deformation Caused by Contact}

When the tooth surface temperature changes, the actual gear tooth profile will not coincide with the theoretical tooth profile and the tooth profile deformation occurs. Do not consider the influence of other factors on the gear except the temperature change, the expression of the time-varying tooth profile deformation which is caused by tooth contact temperature is expressed as follows:

$$
\begin{aligned}
& \sigma_{i}(t)=\left[\frac{l_{i}}{r_{b i}}-2\left(i n v \alpha_{k i}-i n v \alpha\right)\right] \times \\
& \frac{-\Delta(t) \lambda r_{b i}\left(r_{b i}+u_{b i}\right)}{2 \times\left[r_{b i}+u_{b i} \cos \alpha_{k i}+\Delta(t) \lambda r_{b i}\left(1-\cos \alpha_{k i}\right)\right]}
\end{aligned}
$$

In the formula, $\Delta(t)$ is the difference between the contact temperature in the case which gear is into a stable state and the tooth surface temperature in the initial state.

$$
\Delta(t)=\Delta_{B}(t)-\Delta_{0}
$$

The variable feature $l_{i}(i=1,2)$ is the thickness of gear tooth ${ }^{(m)} ; l$ is the linear expansion coefficient of the material; $a_{k i}(i=1,2)$ is the pressure angle of addendum circle ${ }^{\left({ }^{\circ}\right)}$.

$$
a_{k i}=\operatorname{arcos}\left(\frac{r_{b i}}{r_{a i}}\right)
$$

In the formula(8), inva is involute function, inva $=\tan a-a ;{ }_{b i}(i=1,2)$ is the base circle thermal deformation when the system is stable. 


$$
\begin{aligned}
& u_{b i}=\lambda r_{b i} \Delta\left(r_{0 i}\right)+\frac{(1+u) \lambda}{(1-u)} \times \\
& \frac{r_{b i}\left[r_{b i}^{2}(1-2 u)-r_{b i}^{2}\right]}{\left(r_{b i}^{2}-r_{b i}^{2}\right)} \times\left[\Delta\left(r_{b i}\right)-\Delta\left(r_{0 i}\right)\right]
\end{aligned}
$$

Where, $\mathrm{D} r_{0 i}(i=1,2)$ is the gea's temperature when the system is stable $\left.{ }^{(} \mathrm{C}\right) ; \mathrm{D} r_{b i}(i=1,2)$ is the base circle surface's temperature when the system is stable $\left({ }^{\circ} C\right) ; r_{0 i}(i=1,2)$ is the radius of the two gear shafts. Taking the formula(9-11) into equation(8), the deformation of tooth profile which is caused by the change of the tooth contact temperature $s_{i}(t)(i=1,2)$ is obtained. Based on Hertz contact theory, it is assumed that tooth profile deformation is $S$, the normal load of tooth surface is $F_{n}$, the tooth width is $b$, and the stiffness $k_{w}$ which is caused by the change of the tooth contact temperature can be expressed as follows:

$$
k_{w}=\frac{F_{n}}{b s}
$$

Taking the formula(8) and the tooth width $b$ into the formula(12).

$$
k_{w i}(t)=\frac{F_{n}}{b s_{i}(t)}
$$

Due to the track of the gear deformation that caused by the contact temperature is a straight line,the equivalent mesh stiffness $k_{w i}(t)$ can be obtained by connecting the two tooth surface stiffness $k_{w i}(t)(i=1,2)$.

$$
k_{w}(t)=\frac{k_{w 1}(t)^{\prime} k_{w 2}(t)}{k_{w 1}(t)+k_{w 2}(t)}
$$

\section{Nonlinear Dynamics Model}

Based on the theory of concentrated parameters, the dynamic model of the nonorthogonal face gear transmission system is established, which is shown in Fig.1. In the figure, ${ }^{k}$ is the time-varying stiffness coefficient; ${ }^{c}$ is the damping coefficient; $T_{p}$ and $T_{g}$ are torque. 


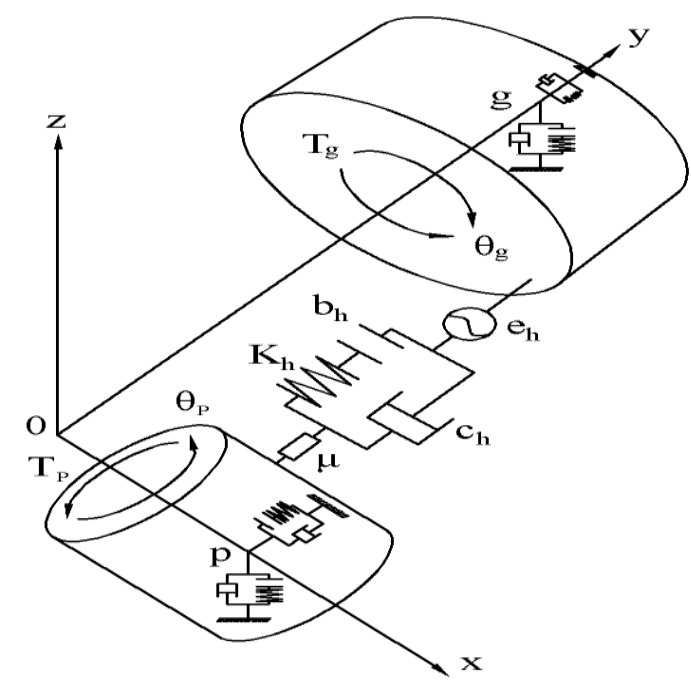

\section{Figure 1. Nonlinear Dynamic Model of Multi-coupled Face Gear Transmission System}

Where, the time-varying stiffness coefficient $k=k_{w}+k_{t}, k_{w}$ is the time-varying stiffness that caused by the contact temperature, $k_{t}$ is the time-varying stiffness that caused by meshing impact. Therefore, according to Fig1, the dynamics equations of the face gear transmission system is expressed as follows:

$$
\left\{\begin{array}{l}
m_{1} \ddot{x}_{1}+c_{x 1} \dot{x}_{1}+k_{x 1} x_{1}=-F_{x} \\
m_{1} \ddot{z}_{1}+c_{z 1} \dot{z}_{1}+k_{z 1} z_{1}=-F_{z} \\
I_{1 y} \ddot{\theta_{y 1}}=T_{1}-F_{n} r_{b 1} \\
m_{2} \ddot{x}_{2}+c_{x 2} \dot{x}_{2}+k_{x 2} x_{2}=-F_{x} \\
m_{2} \ddot{z}_{2}+c_{z 2} \dot{z}_{2}+k_{z 2} z_{2}=-F_{z} \\
I_{2 z} \ddot{\theta}_{z 2}=-T_{2}+F_{n} r_{m}
\end{array}\right.
$$

Where, $m_{1}, m_{2}$ are the quality of the two gears; $I_{1 y}, I_{2 z}$ are moment of inertia; $T_{1}, T_{2}$ are input torque and load torque; $c$ is the support damping.

$$
\begin{aligned}
& x_{n}=\left(x_{1}+r_{1} \theta_{y 1}\right) \cos a_{n}+z_{1} \sin a_{n}- \\
& \left(x_{2}+r_{m} \theta_{z 2}\right) \cos a_{n}-z_{2} \sin a_{n}-e(t)
\end{aligned}
$$

The variable feature ${ }^{x_{n}}$ is the relative displacement; $e(t)$ is the integrated transmission error; ${ }^{a}$ is the normal pressure angle; ${ }^{r}$ is the pitch circle radius; $\theta_{\text {is }}$ the torsion angle; The normal dynamic load that is between the tooth of the face gear transmission is $F_{n}$. 


$$
\left\{\begin{array}{l}
\left.F_{n}=k(t) f\left(x_{n}\right)+c_{m} \dot{x}_{n}\right) \\
F_{x}=F_{n} \cos a_{n} \\
F_{y}=F_{n} \sin a_{n}
\end{array}\right.
$$

Therefore, the second derivative of the relative displacement ${ }^{x_{n}}$ can be expressed as follows:

$$
\left\{\begin{array}{l}
\left(m_{e} \ddot{x}_{n}+a_{2} c_{m} \dot{x}_{n}+k(t) f\left(x_{n}\right) a_{2}\right)-m_{e} \ddot{x_{1}} a_{2}-m_{e} \ddot{z}_{n} a_{2} \\
+m_{e} \ddot{x}_{2} a_{2}+m_{e} \ddot{z}_{2} a_{1}=F a_{2}-m_{e} \ddot{e}(t) \\
m_{e}=\frac{I_{1 y} I_{2}}{I_{1 y} r_{m}^{2}+I_{2 z} r_{b 1}^{2}} \\
F=\frac{T_{1}}{r_{b 1}}=\frac{T_{2}}{r_{m}} \\
a_{1}=\sin a_{n} \\
a_{2}=\cos a_{n}
\end{array}\right.
$$

(18)

Finally, equation(15) can be converted to the equation(19)

$$
\left\{\begin{array}{l}
m_{1} \ddot{x}_{1}+c_{x 1} \dot{x}_{1}+k_{x 1} x_{1}=-a_{2} k(t) f\left(x_{n}\right)-a_{2} c_{m} \dot{x}_{n} \\
m_{1} \ddot{z}_{1}+c_{z 1} z_{1}+k_{z 1} z_{1}=-a_{1} k(t) f\left(x_{n}\right)-a_{1} c_{m} \dot{x}_{n} \\
m_{2} \ddot{x}_{2}+c_{x 2} \dot{x}_{2}+k_{x 2} x_{2}=a_{2} k(t) f\left(x_{n}\right)+a_{2} c_{m} \dot{x}_{n} \\
m_{2} z_{2}+c_{z 2} z_{2}+k_{z 2} z_{2}=a_{1} k(t) f\left(x_{n}\right)+a_{1} c_{m} \dot{x}_{n} \\
m_{e} \ddot{x}_{n}+a_{2} c_{m} \dot{x}_{n}+k(t) f\left(x_{n}\right) a_{2}=m_{e} \ddot{x}_{1} a_{2} \\
+m_{e} z_{n} a_{2}-m_{e} \ddot{x}_{2} a_{2}-m_{e} \ddot{z}_{2} a_{1}+F a_{2}-m_{e} \ddot{e}(t)
\end{array}\right.
$$

To delimit the dimensionless time ${ }^{\tau=t \omega_{n}}$ and the displacement scale ${ }^{b}$, the dimensionless treatment of the formula(19)can be expressed: 


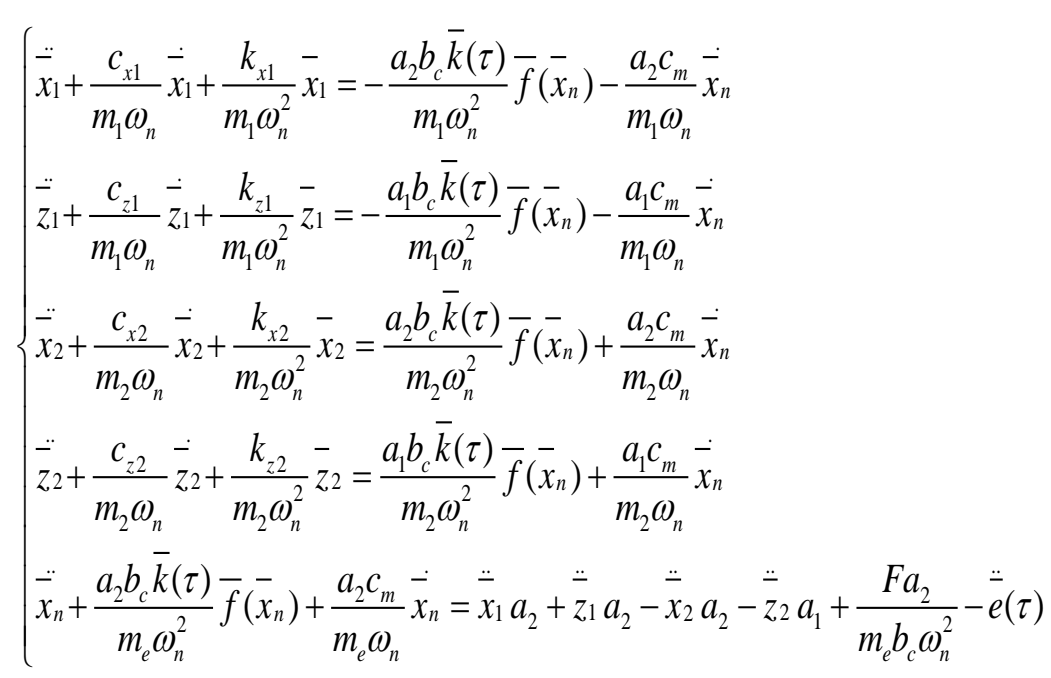

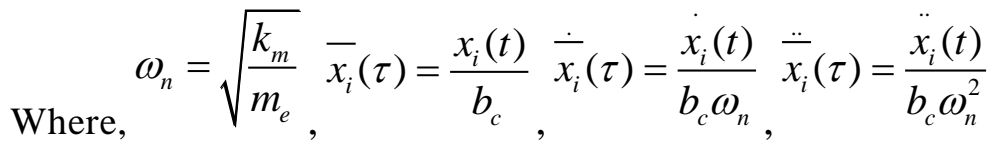

In the equation(20), $\quad k_{z i}=k_{z i t}(t)+k_{z i w}(t),(i=1,2), k_{x i}=k_{x i t}(t)+k_{x i w}(t),(i=1,2) \quad$ The dimensionless gap function of gear can be obtained.

$$
\bar{f}\left(\bar{x}_{n}\right)=\left\{\begin{array}{l}
\bar{x}_{n}-\frac{b}{b_{c}}, \bar{x}_{n}>\frac{b}{b_{c}} \\
0,-\frac{b}{b_{c}}<\bar{x}_{n}<\frac{b}{b_{c}} \\
\bar{x}_{n}+\frac{b}{b_{c}}, \bar{x}_{n}<-\frac{b}{b_{c}}
\end{array}\right.
$$

\section{Analysis of Tooth Surface Contact Temperature}

According to face gear transmission system dynamics model established above, the selected parameters in the table as follows.

Table 1. The Main Parameters of the Face Gear Transmission

\begin{tabular}{c|c|c|c|c|c|c}
\hline Name & Code $/$ unit & Gear1 & Gear2 & Gear3 & Gear4 & Gear5 \\
\hline $\begin{array}{c}\text { Modulus } \\
\text { Cylindrical } \\
\text { gear }\end{array}$ & $m / \mathrm{m}$ & 6 & 6 & 4 & 6 & 6 \\
Face gear & $z_{1}$ & 24 & 28 & 28 & 28 & 28 \\
Pressure angle & $z_{2}$ & 100 & 100 & 100 & 100 & 100 \\
$\begin{array}{c}\text { Body } \\
\text { temperature } \\
\text { Dynamic } \\
\text { viscosity of } \\
\text { lubricants } \\
\text { Power }\end{array}$ & $a_{n}$ & 20 & 18 & 20 & 20 & 20 \\
$\Delta_{0} /{ }^{\circ} \mathrm{C}$ & 65 & 65 & 65 & 65 & 65 \\
& $T_{p} / m P a \llbracket s$ & 65 & 65 & 65 & 65 & 65 \\
& $W_{p} / k W$ & 100 & 100 & 100 & 100 & 100
\end{tabular}




\begin{tabular}{|c|c|c|c|c|c|c|}
\hline $\begin{array}{l}\text { Tooth surface } \\
\text { roughness }\end{array}$ & K/um & 0.2 & 0.2 & 0.2 & 0.2 & 0.2 \\
\hline Density & $\rho / \mathrm{kg} / \mathrm{m}^{3}$ & 7790 & 7790 & 7790 & 7790 & 7790 \\
\hline $\begin{array}{l}\text { Specific heat } \\
\text { capacity }\end{array}$ & $c / J /\left(k g \square^{\circ} C\right)$ & 470 & 470 & 470 & 470 & 470 \\
\hline $\begin{array}{l}\text { Thermal } \\
\text { Conductivity }\end{array}$ & $g / m \square s \square^{\circ} C$ & 43.2 & 43.2 & 43.2 & 43.2 & 43.2 \\
\hline $\begin{array}{c}\text { Rotational } \\
\text { speed }\end{array}$ & $n$ & 10000 & 10000 & 10000 & 19000 & 10000 \\
\hline
\end{tabular}

When the face gear transmission system is in the meshing process, the flash temperatures are existing in the gear meshing tooth surfaces. The same body temperature, power, tooth surface roughness, density, specific heat capacity and thermal conductivity are selected, and study it through the transmission ratio, modulus, pressure angle and speed aspects respectively.

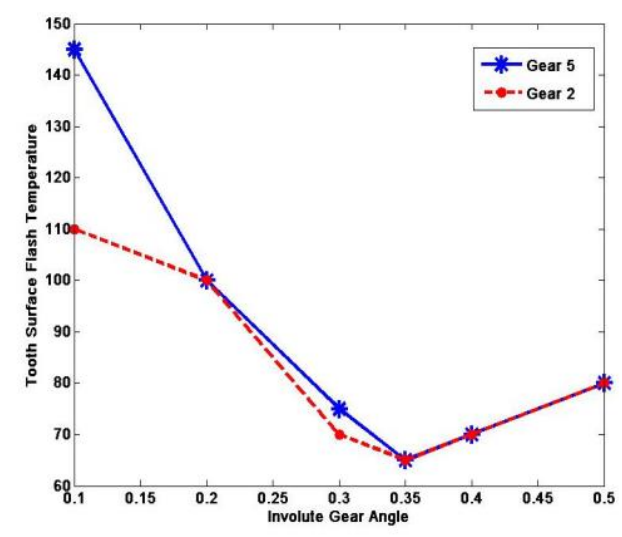

Figure 2. The Temperature Response when $z_{1}=24, z_{2}=28$

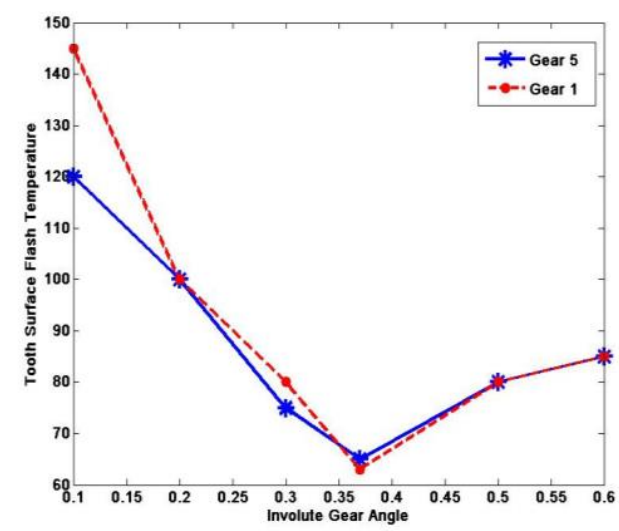

Figure 3. The Temperature Response when $a_{1}=18^{\circ}, a_{2}=20^{\circ}$ 


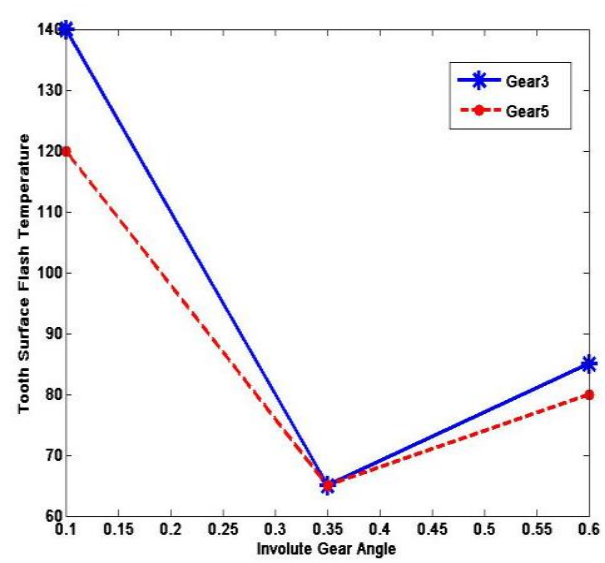

Figure 4. The Temperature Response when $m_{1}=4, m_{2}=6$

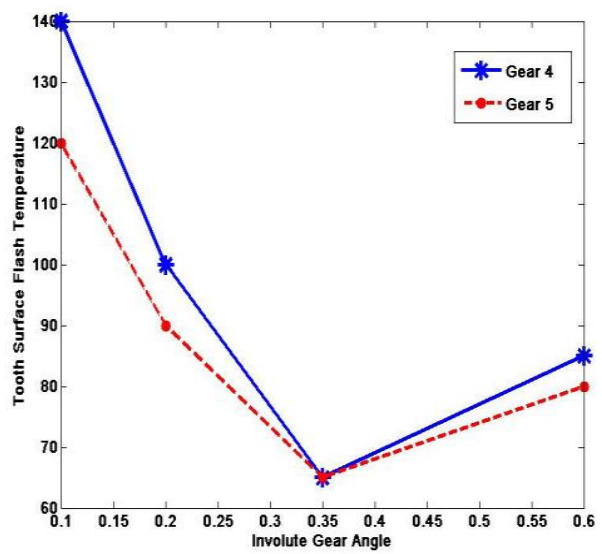

Figure 5. The Temperature Response when $n_{1}=10000, n_{2}=19000$

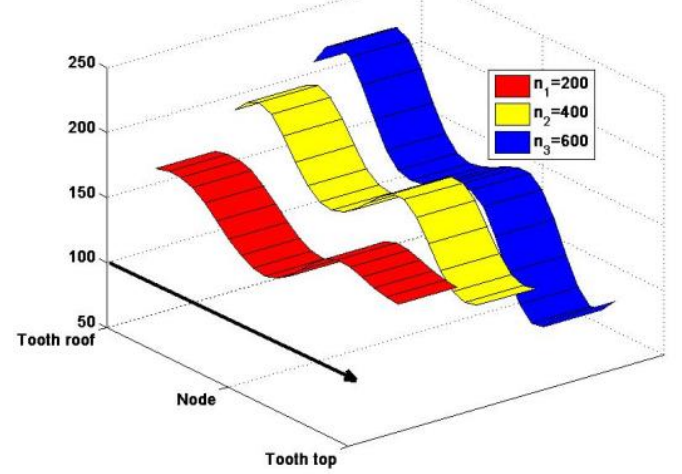

Figure 6. Temperature Distribution of the Contact Surface of the Face Gear 
In the Figure.2,the tooth number of cylindrical gear in the two face gear transmission system are different, $z_{1}=24, z_{2}=28$; In the Figure.3, the pressure angle in the two face gear transmission system are different, $a_{1}=18^{\circ}, a_{2}=20^{\circ}$; In the Figure.4, the modulus are respectively $m_{1}=4, m_{2}=6$; In the Figure.5, the Rotational speed are respectively $n_{1}=10000, n_{2}=19000$.It can be seen from the Figure 2-4,when the gear is entering and exiting engagement, the maximum instantaneous tooth surface temperature will rise higher, the relative velocity direction which is close to the high and middle position of the tooth will change, and the change of parameter will change the temperature. When the gear system is designed, under the circumstances that face gear is certain, it is better for using larger modulus and pressure angle as far as possible. To increase the cylindrical gear teeth can help to reduce tooth surface transient temperature rise and increase the tooth surface's ability of resistance to bonding.Fig.5 shows that the face gear has its broad application prospects in the high-speed and heavy-duty gear drive.Fig.6 shows the temperature distribution of the contact surface of the face gear. The instantaneous contact temperature of teeth appears two peak values in the vicinity of the pitch line of the top surface and the root surface, and the maximum temperature appears on the top surface of the tooth. So the speed is higher, the change of momentary-contact temperature of the teeth is more obvious and the increase of the amplitude is greater.

\section{Conclusion}

(1)Base on the Block theory, the expressions of change of tooth surface flash temperature have been obtained, and on the basis of it, the expressions of change of tooth surface contact temperature have also been solved.

(2)According to the effects of the time-varying temperature of the tooth and the profile of the tooth, the expressions of the profile of the tooth which is changed form the time-varying temperature of the tooth are derived.

(3)Base on the Hertz contact theory, the expressions of change of the stiffness are deduced, simultaneously, by putting the two stiffness variation in series according to the stiffness equivalence principle.

(4)The produce of temperature stiffness makes a significant impact on the dynamic performance of the gear system. To together the temperature stiffness and the meshing stiffness caused by impact as the overall time-varying meshing stiffness,and the nonlinear dynamical model of surface gear transmission considering contact temperature of the tooth has been established.

(5)The analysis of dynamic impact on the tooth surface caused by the friction coefficient, load and flash temperature has obtained by numerical calculation, and the flash temperature is increase as larger as the friction coefficient and load.The flash temperature increase obviously at the top and the root of teeth where is more likely to occur tooth surface gluing.

(6)The results show that flash temperature reaches the maximum at the top and the root of teeth, and in the vicinity of the node is close to zero.This indicates that the tooth surface flash temperature calculation method established in this pape reflects the case of the change in temperature and the sliding gear in a certain extent.The method has certain scientific,and its basic law will be correct in the calculation of the change of tooth surface temperature. 


\section{Acknowledgement}

This research was supported by the Key Program of National Natural Science Foundation of Heilongjiang No.ZD201309, and Project supported by the Major International Joint Research Program of China (Grant No. 2014DFB70120), and the outstanding youth science fund of Heilongjiang (Grant No. JC201420)

\section{References}

[1] G. Deng, M. Kato, N. Maruyama, "Initial Temperature Evaluation for Flash Temperature Index of Gear Tooth", Journal of Tribology, vol. 117, no. 2, (1995), pp. 476-481.

[2] M. Taburdagitan, M. Akkok, "Determination of surface temperature rise with thermo-elastic analysis of spur gears”, Wear, vol. 261, no. 5-6, (2006), pp. 656-665.

[3] M. Vaishya, R. Singh, "Sliding Friction-induced Nonlinea- rity And Parametric Effects In Gear Dynamics", Journal of Sound and Vibration, (2001), vol. 248, no. 4, pp. 671-694.

[4] M. Vaishya, R. Singh, "Strategies for Modeling Friction in Gear Dynamics", Journal of Mechanical Design, vol. 125, no. 2, (2003), pp. 383-393.

[5] T. Fakhfakh, L. Walha, J. Louati, "Effect of manufacturing and assembly defects on two-stage gear systems vibration", The International Journal of Advanced Manufacturing Technology, vol. 29, no. 9-10, (2006), pp. 1008- 1018

[6] L. Walha, T, Fakhfakh, M. Haddar, "Backlash effect on dynamic analysis of a two-stage spur gear system", Journal of Failure Analysis and Prevention. (2006), vol. 6, no. 3, pp. 60-68.

[7] H. Block, "Temperature rise at surface of actual contact under oiliness lubrication conditions", Proceedings of the General Discussion on Lubricaion. Lubricants, London, (1937), pp. 222- 235.

[8] R. Althoff, J. H. Hertz, "Measurement of the optical constants of $\mathrm{Na}$ and $\mathrm{K}$ in the range of wavelength from 2.5 to $10 \mu[\mathrm{J}]$. Infrared Physics,( 1967), vol. 7, no. 1, pp.11-16. 
International Journal of Control and Automation Vol. 8, No.4 (2015) 